\title{
A SPECIAL DEDICATION TO ISRAEL CARMI
}

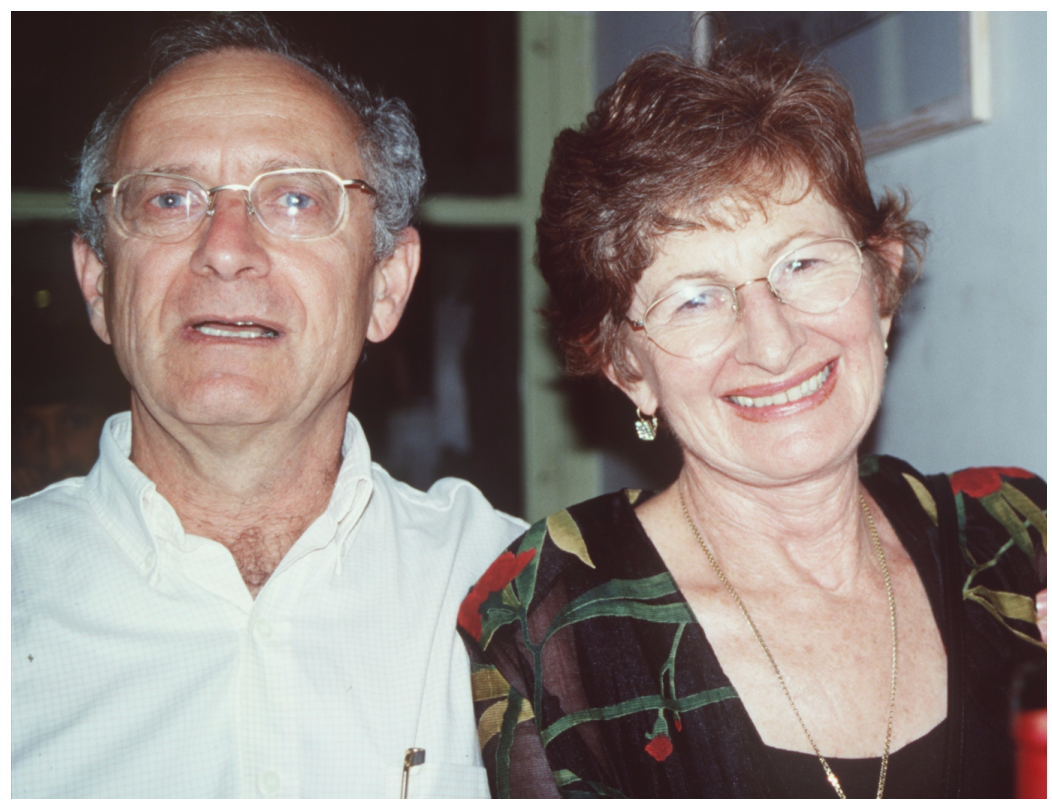

Israel Carmi and his wife, Shulamit, at a reception at MaaleHa'Hamisha during the conference

Israel Carmi, the chairman of the 17th Radiocarbon Conference, wrote in his editorial of the Proceedings that he has devoted the last year to the preparation of these three books. In fact this major effort on his part coincides with the conclusion of his official career as director of the Rehovot Radiocarbon Laboratory; a position he held for 32 years.

The first radiocarbon analyses were performed at the Weizmann Institute of Science, Rehovot, in 1970. The motivation for doing these analyses was mainly for hydrological research. Before that, Israel Carmi started his career by measuring tritium in rain and ground water. In 1970 he integrated the tritium laboratory with the radiocarbon laboratory to establish what is now known as the Radiocarbon Dating Laboratory of the Weizmann Institute. At that time proportional gas counting was used and the gas counters were shielded by 8 tons of iron that were obtained from an old dismantled ship. It was a big effort to clean with acid and prepare those shields for the detector. But Israel remembers those first days with a smile. It must have been some fun too.

The first radiocarbon sample was atmospheric $\mathrm{CO}_{2}$ and the first list of measurements was published in 1971. Most of the samples were water from various sources and of geological origin. One of the highlights of the hydrological research that the laboratory was involved in was the use of tritium to determine the rate of water upward transport through the sediments of Lake Kinneret. In the mid1980 s the laboratory switched from gas counting to scintillation counting. This also more or less coincided with a decision to broaden the activities of the laboratory to also include archaeological samples. This was motivated by the desire to contribute to our understanding of the very rich archaeological record of the Levant. Today the major focus of the Laboratory is on archaeology, with inhouse preparation of samples for AMS, as well as complete analyses using 3 liquid scintillation counters. Tritium analyses of hydrological samples are still continued. 
Of the many archaeological samples that Israel Carmi has dated, the ones he was perhaps most excited about were from the so-called Kinneret boat. The wood of the boat dated to 40 BC-120 AD. For this and other reasons, the boat became known as the "Boat of Jesus". Israel Carmi was also involved in the initial organization and sampling of the Dead Sea Scrolls; a major project of the dating community, with the first dates being carried out in collaboration with the AMS Laboratory at ETH in Zurich.

I have had the opportunity to work with Israel during the preparation of this conference and for a year he taught me how to run the Laboratory before having the honor of taking over the directorship from him. I have learned a lot from Israel, and our interactions have always been lots of fun. All of you who know Israel, or who met him for the first time at the conference, will appreciate his sensitivity, optimism, modesty and quiet disposure (compared to me!). He is, in short, a positive spirit.

The idea of holding the 17th Radiocarbon Conference in Israel was first presented by Israel Carmi in Glasgow. It became a major project when in Groningen the community voted in favor, and it finally became a reality in MaaleHa'Hamisha with Israel Carmi organizing a beautiful week in June 2000. His timing was perfect. It is not easy to get all your friends to come from all over the world for a week-long retirement party. After all, it took Israel 6 years!

Thank you, Israel, for being the initiator and the organizer of such a wonderful conference.

\section{Elisabetta Boaretto}

Guest editor and conference secretariat 